\title{
A Study on the Neurotoxicity of Flunitrazepam (Rohypnol) Administration on the Cerebral Cortex of Adult Wistar Rats
}

\author{
Udodi Princewill Sopuluchukwu*, Ezejindu Damian Nnabuihe \\ Department of Anatomy, Nnamdi Azikiwe University, Anambra State, Nigeria \\ Received February 11, 2021; Revised March 29, 2021; Accepted April 22, 2021
}

\section{Cite This Paper in the following Citation Styles}

(a): [1] Udodi Princewill Sopuluchukwu, Ezejindu Damian Nnabuihe, "A Study on the Neurotoxicity of Flunitrazepam (Rohypnol) Administration on the Cerebral Cortex of Adult Wistar Rats," Advances in Pharmacology and Pharmacy, Vol. 9, No. 2, pp. 26 - 32, 2021. DOI: 10.13189/app.2021.090202.

(b): Udodi Princewill Sopuluchukwu, Ezejindu Damian Nnabuihe (2021). A Study on the Neurotoxicity of Flunitrazepam (Rohypnol) Administration on the Cerebral Cortex of Adult Wistar Rats. Advances in Pharmacology and Pharmacy, 9(2), 26 - 32. DOI: 10.13189/app.2021.090202.

Copyright $\bigcirc 2021$ by authors, all rights reserved. Authors agree that this article remains permanently open access under the terms of the Creative Commons Attribution License 4.0 International License

\begin{abstract}
Flunitrazepam (Rohypnol) is a benzodiazepine drug medically proscribed in United States whereas it's legally prescribed in over sixty nations where the drug is administered as pre-anesthetic drug and in the treatment of insomnia but not without the loss of cerebral cortex functions which inspired this investigation to establish its neurotoxicity on the cerebral cortex of adult wistar rat. Sixteen adult female wistar rats were randomly divided into four groups with four rats in each group (A, B, $\mathrm{C}$ and $\mathrm{D}$ ). Group $\mathrm{A}$, the control group received distilled water. Groups B, C and D received $1 \mathrm{mg} / \mathrm{kg}, 2 \mathrm{mg} / \mathrm{kg}$ and $3 \mathrm{mg} / \mathrm{kg}$ of Flunitrazepam (Rohypnol) respectively. The animals were sacrificed after three weeks of administration and the cerebral cortexes were harvested and fixed in $10 \%$ formal saline for histological processing and studies. The anthropometric investigation presented an insignificant increase in the relative body weight of the test groups when compared to the control group and also presented a significant increase in the relative organ weight in the entire test groups when compared to the control group. The cerebral cortex of experimental animals showed; severe lymphocytic infiltration, focal areas of liquefactive necrosis, intracerebral hemorrhage, vacuolation and various degrees of damages to the tissue layers and neuronal cells of the cerebral cortex. This scientific investigation indicates that consumption of Flunitrazepam (Rohypnol) across various graded doses causes changes in the cerebral cortex histoarchitecture which explains the
\end{abstract}

rationale behind the loss of cerebral cortex function in drug addicts and patients placed on prolonged Flunitrazepam (Rohypnol) therapy.

$\begin{array}{llr}\text { Keywords } & \begin{array}{l}\text { Histological, } \\ \text { (Rohypnol), }\end{array} & \text { Cerebral Cortex, } \\ \text { Flunitraztoarchitecture, }\end{array}$

Benzodiazepine

\section{Background of the Study}

Flunitrazepam (Rohypnol) is a benzodiazepine producing sedative, anxiolytic, hypnotic, anticonvulsant, and muscle relaxant effects in humans and rodents [1]. Most countries where the drug is legally approved, it is administered as a pre-anesthesia and in the treatment of insomnia; these were the original indications of the drug [2]. Flunitrazepam (Rohypnol) should be administered just as other hypnotic drugs, strictly in a short-term basis, or occasionally with caution in cases of chronic insomnia [3].

Flunitrazepam (Rohypnol) is medically proscribed in United States whereas it's legally prescribed in over sixty nations inclusive of Colombia, Mexico and most European countries where the drug is administered as pre-anesthetic drug and in the treatment of insomnia [4].

The major pharmacological effect of Flunitrazepam 
(Rohypnol) as a Lipophilic drug is its enhancement of Gamma-aminobutyric acid (GABA) at the localized GABA receptors [5]. A study of 53 women who were exposed to Flunitrazepam (Rohypnol) for recreational purpose revealed that $10 \%$ of the subjects under the control of Flunitrazepam (Rohypnol) were sexually molested or physically assaulted [6]. People under the impact of Flunitrazepam (Rohypnol) abuse may experience a state of dissociation or automatism which the user may find it difficult to remember what occurred while under the influence after the drug wears off. The impact of Flunitrazepam (Rohypnol) consumption may leave the patients with the following clinical conditions; sluggish and uncoordinated movement of the limbs, hung-over, anterograde amnesia, woozy feelings, stomach upset, dizziness and confusion [6-8]. An Abrupt withdrawal of Flunitrazepam (Rohypnol) therapy may present a clinical condition referred to as benzodiazepine withdrawal syndrome characterized by the following symptoms; Insomnia, Psychosis, seizures, and anxiety [9].

Cerebral cortex also called cerebral mantle, is the largest part of the mammalian brain which plays an important role in cognition, memory, perception, thought, consciousness, attention, awareness and language [10]. Since Flunitrazepam (Rohypnol) has been established to have clinical conditions associated with the loss of cerebral cortex functions thus, this research work aims to establish the neurotoxicity of Flunitrazepam (Rohypnol) on the cerebral cortex of adult wistar rat.

\section{Materials and Methods}

Location and Duration of Study: This scientific investigation was carried out in the Department of Anatomy, Faculty of Basic Medical Sciences, College of Health Science, Nnamdi Azikiwe University, Anambra State Nigeria. The animals were procured from the animal house of the department of Anatomy, and the animals were allowed to acclimatize for a sufficient period of two weeks before the administration of Flunitrazepam (Rohypnol) for a considerable period of 21days. The entire experiment lasted for a total of five weeks.

Ethical Approval: The ethical committee of the department of Anatomy College of Health Sciences, Nnamdi Azikiwe University, Anambra state, ascertained and approved this scientific investigation.

Experimental Animals: Sixteen (16) female albino rats weighing $100-150 \mathrm{~g}$ were procured from a laboratory at Nnamdi Azikiwe University Nnewi campus and housed at the animal house of the Department of Anatomy, College of Health Sciences Nnamdi Azikiwe University Nnewi, Anambra State. The rats were marked with various colors peculiar with each group, and were housed in plastic cages with iron net in standard condition. The rats were fed sufficiently with normal grower mesh produced by Premier Feed Mills Co. Limited (A subsidiary of Flour Mills Nigeria Plc). The animals were grouped into four; Group 1 represents the control group while Groups 2, 3 and 4 represents the test group. All rats were weighed prior to the commencement of administration and subsequently weighed weekly (once a week) using Melter's Electronic weighing balance model PB303 (made by Monobloc in Switzerland).

Drug: Flunitrazepam (Rohypnol) was produced and marketed by SWISS Pharma Nigeria LTD. No 5, Dopemu Road, Agege, Lagos state. Under the license of Global Healthcare Ltd, Basel Switzerland.

Experimental Design: The animals were grouped at random into four with four animals in each of the groups. The test animals were administered Flunitrazepam (Rohypnol) for 21days in graded doses of $1 \mathrm{mg} / \mathrm{kg}$ for group B, $2 \mathrm{mg} / \mathrm{kg}$ for group C, and $3 \mathrm{mg} / \mathrm{kg}$ for group D while group A which is the control group received only distilled water.

\begin{tabular}{|c|c|c|c|}
\hline S/N & Group & Water + rat feed & Duration \\
\hline 1 & A (Control) & & 21days \\
\hline 2 & B & $\begin{array}{c}1 \mathrm{mg} / \mathrm{kg} \text { of Flunitrazepam } \\
\text { (Rohypnol) }\end{array}$ & 21days \\
\hline 3 & $\mathrm{C}$ & $\begin{array}{c}2 \mathrm{mg} / \mathrm{kg} \text { of Flunitrazepam } \\
\text { (Rohypnol) }\end{array}$ & 21days \\
\hline 4 & $\mathrm{D}$ & $\begin{array}{c}3 \mathrm{mg} / \mathrm{kg} \text { of Flunitrazepam } \\
\text { (Rohypnol) }\end{array}$ & 21days \\
\hline
\end{tabular}

Organ Collection: The rats were sacrificed after 21days of administration of Flunitrazepam (Rohypnol) in graded doses. The cerebral cortexes were then harvested and put in a normal saline to maintain normal physiological conditions after which they were weighed and fixed in 10\% formal saline for Histological processing.

Tissue Processing: After weighing the organs, a small part of the cerebral cortex tissues were cut out and immediately fixed in $10 \%$ formal saline in order to preserve the various constituents of the cells in their normal microanatomical positing and to prevent autolysis and putrefaction. After fixation the tissues were dehydrated to remove water and other substances. This was carried out in different percentages of alcohol 50\%, $70 \%$ and $95 \%$ absolute. In each grade of alcohol, tissues were changed twice for two (2) hours, one (1) hour for each change. After dehydration, tissues were cleared in xylene for two (2) hours after which infiltration was done in molten paraffin wax at a temperature of 60oc for two (2) hours, each in two changes. When the paraffin wax cools, it sets as a hard block which allows for easy sectioning of the tissues. The tissue sections were produced by normal histochemical methods of dehydration, clearing, impregnation, embedding, sectioning and staining (with H\&E). The micrographs of the relevant stained sections were subsequently taken with the aid of a light microscope.

Statistical Analysis: The data were analyzed using SPSS version 23. Values were represented as MEAN and 
SEM, Relative Organ weight (Brain) were analyzed using One way ANOVA, followed by Post Hoc LSD multiple comparism. Body weight was analyzed using Student dependent T-test. Values were considered significant at $\mathrm{P}<0.05$.

\section{Result}

Physical and Behavioural Changes: slow and staggered movements were observed when administered Flunitrazepam (Rohypnol) at graded dosage. There were also weakness and weight gain.

Effect of Flunitrazepam (Rohypnol) on the Body Weight: The scientific investigation on the effect of Flunitrazepam (Rohypnol) administration on the body weight of adult wistar rat, presented the following data which are represented in table and bar chart. The data were obtained before and after the administration.

Table 1. The effect of Flunitrazepam (Rohypnol) (flunitrazepam) on the body weight of adult wistar rats

\begin{tabular}{|c|c|c|c|c|c|}
\hline \multicolumn{6}{|c|}{ Body weight (g) } \\
\hline & & Mean & \pm SEM & P-Value & T-Value \\
\hline \multirow{2}{*}{ Group 1} & Initial & 112.50 & \pm 4.78 & & \\
\hline & Final & 147.50 & \pm 2.50 & $0.001 *$ & -12.124 \\
\hline \multirow{2}{*}{ Group 2} & Initial & 127.50 & \pm 13.14 & & \\
\hline & Final & 137.50 & \pm 15.47 & 0.721 & -0.392 \\
\hline \multirow{2}{*}{ Group 3} & Initial & 105.00 & \pm 5.00 & & \\
\hline & Final & 125.00 & \pm 5.00 & 0.092 & -2.449 \\
\hline \multirow{2}{*}{ Group 4} & Initial & 92.50 & \pm 4.78 & & \\
\hline & Final & 105.00 & \pm 8.66 & 0.342 & -1.127 \\
\hline
\end{tabular}

Data were analyzed using Student dependent T-test and values were considered significant at $\mathrm{P}<0.05$. $* \mathrm{P}<0.05$ means significant. $\mathrm{P}>0.05$ Not Significant.

Result from the table 1 show that there was a significant increase in the body weight in group 1 when comparing the Initial weight $(112.50 \pm 4.78)$ to the Final weight (147.50 \pm 2.50$)$. In group 2, there was an insignificant increase in the body weight when comparing the Initial weight (127.50 \pm 13.14$)$ to the Final weight (137.50 15.47$)$. In group 3, there was an insignificant increase in the body weight when comparing the Initial weight $(105.00 \pm 5.00)$ to the Final weight $(125.00 \pm 5.00)$. In group 4 , there was an insignificant increase in the body weight when comparing the Initial weight $(92.50 \pm 4.78)$ to the Final weight $(105.00 \pm 8.66)$.

\section{Effect of Rohypnol (Flunitrazepam) on Body Weight}

\section{Initial weight (g) $\quad$ Final weight (g)}

147.5

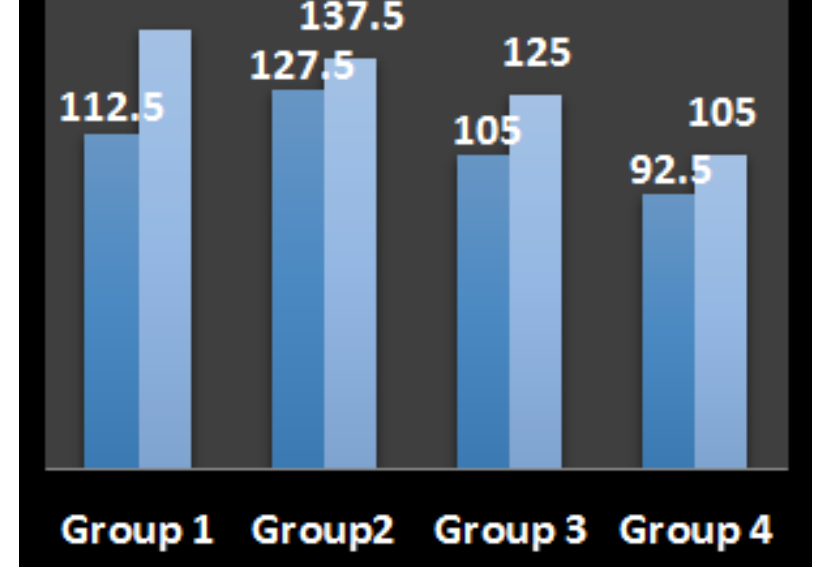

Figure 1. Bar chart showing the effect of Flunitrazepam (Rohypnol) (flunitrazepam) on the body weight of adult wistar rat.

Effect of Flunitrazepam (Rohypnol) on the Organ Weight: The scientific investigation on the effect of Flunitrazepam (Rohypnol) administration on the organ weight of adult wistar rat, presented the following data which are represented in table and bar chart. The data were obtained immediately after the organs were harvested.

Table 2. The effect of Flunitrazepam (Rohypnol) (Flunitrazepam) on the Brain (Cerebral Cortex) relative weight of adult wistar Rats

\begin{tabular}{cccccc}
\hline & & Mean & \pm SEM & P-value & F-value \\
\hline & Group 1 & 0.62 & \pm 0.01 & & \\
$\begin{array}{c}\text { Relative } \\
\text { Brain Weight } \\
(\text { g) }\end{array}$ & Group 2 & 0.71 & \pm 0.02 & $0.007^{*}$ & 12.027 \\
& Group 3 & 0.78 & \pm 0.01 & $0.006^{*}$ & \\
\hline
\end{tabular}

All data were analyzed using One-way Anova, followed by multiple comparisons using LSD, and data were considered significant at $\mathrm{P}<0.05$. $* \mathrm{P}<0.05$ shows that it was significant, and $\mathrm{P}>0.05$ shows not significant. 
Result from the table 2, the Relative brain weight result showed a significant increase in group $2(0.71 \pm 0.02), 3$ $(0.78 \pm 0.01)$, and $4(0.82 \pm 0.03)$ when compared to group 1 $(0.62 \pm 0.01)$.

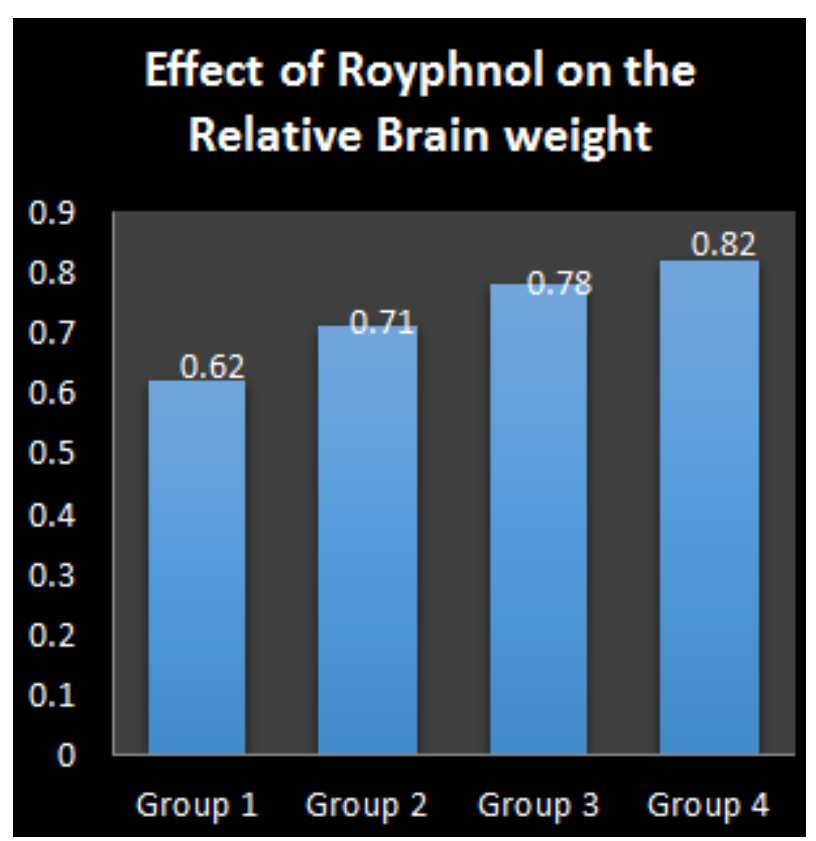

Figure 2. Bar chart showing the effect of Flunitrazepam (Rohypnol) (flunitrazepam) on the relative weight of the brain

Histopathological Findings: The following are the histological findings observed in the course of investigating the effect of Flunitrazepam (Rohypnol) administration on the cerebral cortex of adult wistar rat. The histological results obtained are the representation of the tissues and the cells of the cerebral cortex following the variable grades of Flunitrazepam (Rohypnol) administration.

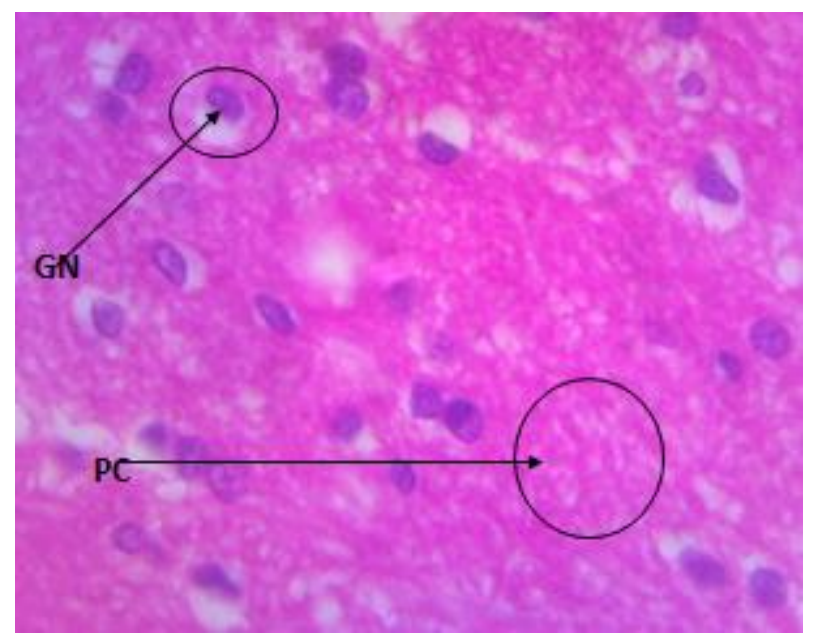

Plate 1. (Group1- Control)- A photomicrograph section of cerebral cortex showing normal giant neuronal cells (GNC) and Pyramidal cells (PC). Stained by H \& E technique (X 400)

The Micrograph plate 1 shows normal Giant neuronal cells of the cerebrum with the densely stained large eccentrically located nucleus. The giant cells are evenly distributed around the tissue with most of the cells clustered in two and three. The pyramidal cells are observed arranged in sheaths with stained pink nucleus and it cytoplasm.

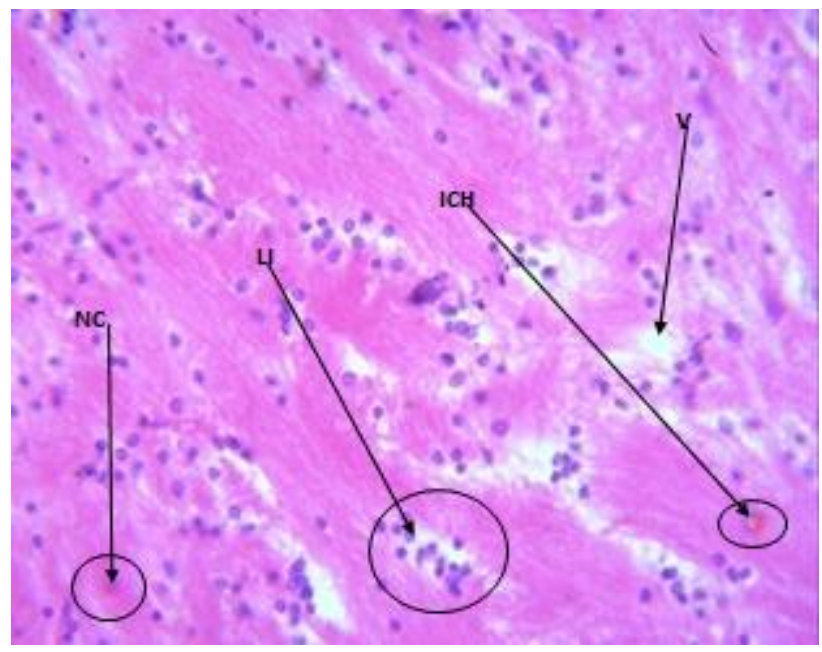

PLATE 2. (GROUP 2)- A Photomicrograph section of cerebral cortex induced with $1 \mathrm{mg}$ of Flunitrazepam (Rohypnol) showing mild damage on the cells and tissues of cerebral cortex with necrotic cells (NC), lymphocytic infiltration (LI), vacuolations (V) and Intracerebral Hemorrhage (ICH). Stained by H \& E technique (X400)

The Micrograph plate 2 shows an onset of tissue necrosis with an excessive lymphatic infiltration. Most of the Giant and Pyramidal cells lost their cell cytoplasm and membranes which results to the vacuolations presented in the micrograph above. The tissue also showed commensurate level of hemorrhage which symbolizes injury to the blood vessels around the cerebrum.

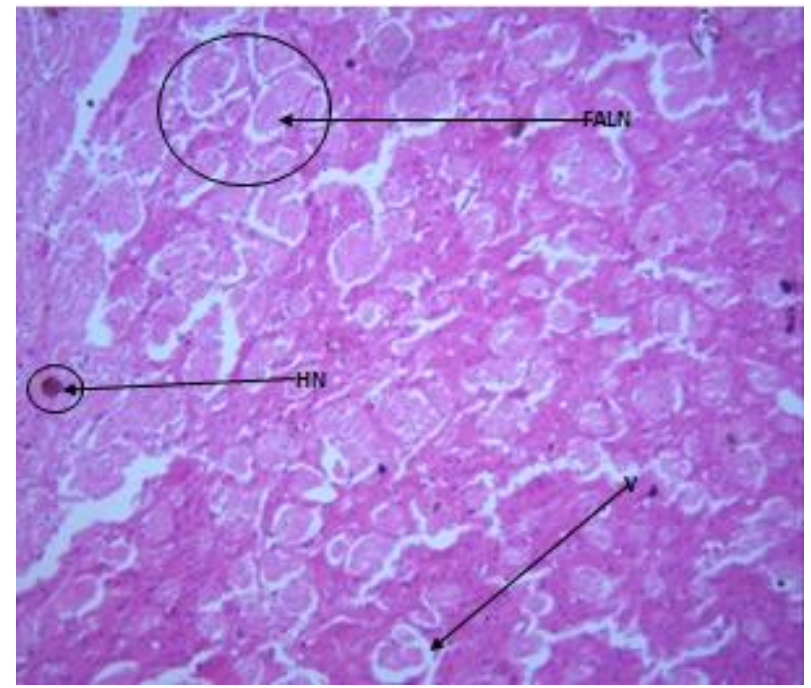

PLATE 3. (GROUP 3)- A Photomicrograph section of cerebral cortex induced with $2 \mathrm{mg}$ of Flunitrazepam (Rohypnol) showing severe damage on the cerebral cortex with focal areas of liquefactive necrosis (FALN), vacuolation (V) and Hemorrhagic necrosis (HN). Stained by $\mathrm{H} \& \mathrm{E}$ technique (X400) 
The Micrograph plate 3 shows the presence of deoxygenated blood which signifies the inhibition of venous blood drainage leading to hemorrhagic necrosis. Sufficient tissue necrosis was also observed with severe tissue infiltration by inflammatory cells. The tissue also presents further destruction of the Giant and pyramidal neuronal cell cytoplasm and membranes replaced by vacuolations.

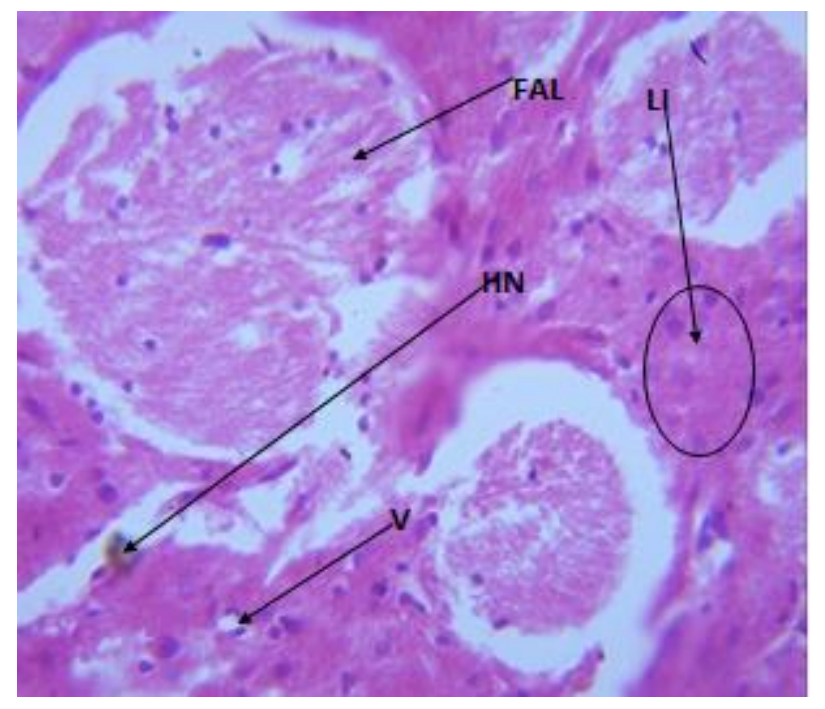

PLATE 4. (GROUP 4)- A Photomicrograph section of the cerebral cortex induced with $3 \mathrm{mg}$ of Flunitrazepam (Rohypnol) shows extensive damage on the cerebral cortex with Focal areas of liquefactive necrosis (FALN), hemorrhagic necrosis (HN), vacuolation and Lymphocytic infiltration (LI). Stained by H \&E Technique (X 400)

Micrograph plate 4 shows a severe level of tissue necrosis with it commensurate level of lymphocytic infiltration. Loss of venous drainage was marked by the presence of hemorrhagic necrosis. The tissue also presents severe destruction of the Giant and pyramidal neuronal cell cytoplasm and membranes replaced by vacuolations.

\section{Discussion}

Flunitrazepam (FNZ) also called Flunitrazepam (Rohypnol) is a potent benzodiazepine agonist primarily used as a hypnotic and preanesthetic agent across Europe $[11,12]$. Flunitrazepam belongs to the sedative group of benzodiazepine administered for short-term insomnia condition at a recommended dose of 0.5-1.0 mg, with a maximum dose of $2.0 \mathrm{mg}$ [13]. Flunitrazepam is increasingly abused among the teeming youth $[12,13]$ and is one of the drugs abused in and in other social settings, including countries, where this drug is not legally available $[11,14,15]$. Relating to other cerebral modulating drugs, FNZ can produce pharmacological effects which include; memory impairment, sedation, and behavioral disinhibition, which is described as an increase in the probability of behaviors that typically occur at low frequencies due to social, culture and interpersonal constraints, such as violence and sexual misconduct. These amnesic and disinhibitory effects might account for the increased risk behavior and altered decision-making, violence, and high-risk sexual activity in patients associated with the abuse of Flunitrazepam [16,17].

Result of the body weight showed there was an insignificant increase in groups $\mathrm{B}, \mathrm{C}$ and $\mathrm{D}$ when compared to the control group. The reason for the insignificant increase in body weight is not understood. This study is in line with work done by [18] who reported an insignificant increase in the body weight when compared with the control. This was on opposition to the study by [19] which reported a significant increase of the body weight in myelopathy patients and also a study by [20] which reported that diazepam showed significant increase in the body weight following chronic administration which was explained by [21] to be as a result of changes in the metabolic rate mediated by action of diazepam at the peripheral benzodiazepine receptors located on the cellular mitochondria. The rationale behind the significant increase in body weight was also given by [22] who proposed that the significant increase in body weight was as a result of longer exposure, followed by the withdrawal of the drugs which could explain the successful alteration of the metabolic activities proposed by [23].

The significant increase in the relative brain weight of wistar rats in group B, C \& D when compared to the control group refutes the scientific investigation by [23] who reported that there was a decrease in the brain weight after one week of exposure to benzodiazepines. Another scientific investigation on the neuro-toxicity and brain tissue HSPs level in Benzo(a)pyrene exposed mice, reported that there were decrease in the relative brain weight of both the high and medium dose when compared to control, but the Low dose had a significant increase in the relative brain weight when compared with control [24].

The histopathological findings in this current study revealed that there was mild to severe damage on the cells and tissues of cerebral cortex with focal area of liquefactic necrosis, hemorrhage, severe lymphocytic infiltration and vacuolations at different graded doses of Royphnol which is synonymous with the research by [25] which presents a damage to the cerebral cortex with extensive neuropil vacuolization, degeneration of pyramidal cells which appeared either darkly or faintly stained cytoplasm with pyknotic nuclei. The rationale behind the extensive damage of cerebral cortex could be said to be the resultant 7-Aminoflunitrazepam which is the toxic metabolite of Flunitrazepam (Rohypnol) having the ability to cross the blood brain barrier and alter the cellular integrity of cerebral cortex. 


\section{Conclusions}

This study reveals the dangerous effect of Flunitrazepam (Rohypnol) therapy which explains the progressive loss of cerebral cortex functions in patients placed on chronic or prolonged Flunitrazepam (Rohypnol) therapy.

\section{Recommendation}

Further investigation should be carried out in other aspect of the brain to ascertain the degree of effect exerted on the brain tissues by Flunitrazepam and also since the blood brain barrier is structured to impaired toxic molecules in the body from entering the brain tissues, the need to subject the proposed rationale behind the extensive destruction of the cells and tissues of cerebral cortex by Flunitrazepam (Rohypnol) administration is expedient to inform proper clinical measures in management of neurodegenerative diseases caused by the substance.

\section{Contributions to Knowledge}

This research work explains the rationale behind the loss of cerebral cortex function in drug addicts and patients placed on prolonged Flunitrazepam (Rohypnol) therapy and may also form a guide for medical practitioners to ensure minimal side effect in administration of Flunitrazepam (Rohypnol) to patients.

\section{Acknowledgements}

This manuscript is based on a research conducted in the department of Anatomy, Nnamdi Azikiwe University. I'm grateful for a number of friends, colleagues and family in their encouragement and support for this research work.

In Niger Delta University Wilberforce Island Bayelsa state, I thank my Mentor and Colleague Dr. Charles Oyinbo, and Mr. Anthony for their unwavering support and encouragement in the course of this research.

In Anambra State Nigeria, I'm indebted to my wonderful friends; Mr. Onyenwife Leonard Chikwado, Mr. Anisiji Ikechukwu for their passionate advice and encouragement throughout this scientific investigation.

Finally I would like to acknowledge with gratitude, the support and love of my family- my parents, Mr. Okechukwu Udodi and Mrs. Uzoamaka Udodi; my brothers; Mara, Chekwube, Makua; my sisters- Sobe, Cheta, Muna. They all were part of my success and this research would not have come true without them.

\section{REFERENCES}

[1] S. File. The history of benzodiazepam dependence: a review of animal studies. Neuroscience and Biobehavioral Review, No.14, 135-146, 1990.

[2] M. A. Mattila, H. M. Larni. Flunitrazepam: a review of its pharmacological properties and therapeutic use. Drugs, Vol.20, No.5, 353-74, 1980.

[3] New South Wales Department of Health. New south wales health alert - warning on e-liquids. Sydney: New South Wales (NSW) Government; 2013.http://www.health.nsw.go v.au/campaigns/quitting_smoking/Pages/e-liquid.aspx

[4] Drugs.com. Commonly abused drugs and substances: Flunitrazepam (Rohypnol); 2020. https://www.drugs. com/illicit/Flunitrazepam (Rohypnol).html

[5] L. M. Hesse, K. Venkatakrishnan, L. L. Von Moltke, R. I. Shader, D. J. Greenblatt. CYP3A4 is the major CYP isoform mediating the in vitro hydroxylation and demethylation of flunitrazepam. Drug Metabolism \& Disposition, Vol.29, No.2, 133-40, 2001.

[6] R. L. Miller. Drugs of abuse: a reference guide to their history and use. Westport, Conn.: Greenwood Press, P.168, 2002.

[7] M. D. Lyman. Practical drug enforcement (3rd Ed.). Boca Raton, Fla.: CRC, P.70, 2006.

[8] O. S John, E. T Brent. Rape investigation handbook (2nded.). Waltham, MA: Academic Press, P. 338-339, 2011.

[9] A. Kales, M. B Scharf, J. D Kales, C. R Soldatos. Rebound Insomnia. A potential hazard following withdrawal of certain benzodiazepines. Journal of the American Medical Association, Vol.241, No.16, 1692-5, 1979.

[10] E. R. Kandel, J. H. Schwartz, T. M. Jessell. Principles of neural science $\left(4^{\text {th }}\right.$ edition). United States of America: Mcgraw-Hill, P.324, 2000.

[11]J. H Woods, G. Winger. Abuse liability of flunitrazepam. Journal of Clinical Psychopharmacology, No.17, 1s-57s, 1997.

[12]H. Druid, P. Holmgren, J. Ahlner. Flunitrazepam: an evaluation of use, abuse and toxicity. Forensic Science International, No.122, 136-141, 2001

[13] T. A. Ohshima. Case of drug-facilitated sexual assault by the use of flunitrazepam. Journal of Clinical Forensic Medicine, No.13, 44-45, 2006.

[14] K. M. Smith, L. L. Larive, F. Romanelli. Club drugs: methylenedioxymethamphetamine, flunitrazepam, ketamine hydrochloride, and gamma-hydroxybutyrate. American Journal of Health System Pharmacology, No.59, 1067-1076, 2002 .

[15] G. C. Britt, E. F. Mc-Cange-Katz. A brief overview of the clinical pharmacology of club drugs. Substance Use Misuse. No.40, 1189-1201, 2005

[16] L. T. Wu, W. E. Schlenger, D. M. Galvin. Concurrent use of methamphetamine, MDMA, LSD, ketamine, GHB, and flunitrazepam among american youths. Drug Alcohol Dependence. No.84, 102-113, 2006.

[17] S. D. Lane, D. R. Cherek, S. O. Nouvion. Modulation of 
Human Risky Decision Making By Flunitrazepam. Psychopharmacology. No.196, 177-188, 2008.

[18] V. E. Grimm, A. Jancourt. The effect of chronic diazepam treatment on body weight and food intake in rats. International Journal of Neuroscience, Vol.18, No.1-2, 127-135, 1983.

[19] J. H. Frisbie, E. J. Aquilera. Diazepam and body weight in myelopathy patients. Journal of Spinal Cord Medicine. Vol.18, No.3, 2002-2, 1995.

[20] M. P. Sunit, S. E. Ivor. The effect of chronic administration of diazepam on $24 \mathrm{hr}$. food intake and body weight gain in non-deprived rats. British Pharmacological Society, No.1, $7-9,2002$

[21]P. Casellas, S. Galiegue, A. Basile. Peripheral benzodiazepine receptors and mitochondrial function. Neurochemistry International, NO.40, 475-486, 2002.

[22] S. K. Kulkarni, K. Anupama, D. Ashish. Effect of withdrawal of diazepam or morphine treatment on gastric motility (charcoal meal test) in mice: possible role of different central and peripheral receptors. Indian Journal of Experimental Biology, NO.45, 642-648, 2007.

[23] L. Marsh, W. McDonald, J. Cummings, B. Ravina. Provisional diagnostic criteria for depression in Parkinson's disease: report of an NINDS/NIMH Work Group. Movement Disorder. No.21, 148-158, 2006.

[24] B. Tu, T. Wu, H. He. Study on the neurotoxicity and brain tissue HSPs level in benzo[a]pyrene exposed mice. Wei Sheng yan jiu- Journal of Hygiene Research, Vol.33, No.1, $15-17,2004$.

[25] M. G. Fatma, A. K. Hanaa, Z. E. Ayman, N. H. Ahmed. Effect of chronic usage of tramadol on motor cerebral cortex and testicular tissues of adult male albino rats and the effect of its withdrawal: histological, immunohistochemical and biochemical study. International Journal of Clinical and Experimental Pathology, Vol.7, No.11, 7323-7341, 2014. 